\title{
Utjecaj tehnologije fermentacije imobiliziranim kvascima na prisutnost biogenih amina u pjenušcu
}

\section{Sažetak}

Novi trendovi na području sigurnosti hrane povećali su fokus na elemente i spojeve u tragovima koji mogu utjecati na ljudsko zdravlje, u koje se ubrajaju i biogeni amini. Biogeni amini su biološki aktivni dušični spojevi male molekulske mase. U vinu mogu nastati iz prekursora, djelovanjem mikroorganizama u bilo kojoj fazi proizvodnje. Cilj ovoga rada bio je ispitati utjecaj fermentacije imobiliziranim kvascima na sadržaj biogenih amina u pjenušcu. Kvantitativno određivanje provedeno je pomoću RP-HPLC (Reversed Phase High Performance Liquid Chromatography) te je utvrđeno da je pjenušac proizveden pomoću imobiliziranih kvasaca sadržavao niži udio biogenih amina $\left(5,41 \mathrm{mgL}^{-1}\right.$ u odnosu na $7,24 \mathrm{mgL}^{-1}$ u klasično proizvedenom).

Ključne riječi: biogeni amini, imobilizirani kvasci, pjenušac

\section{Uvod}

Prisustvo biogenih amina (BA) u vinu sve je važnije kako proizvođačima, tako i potrošačima, jer predstavlja opasnost za zdravlje osjetljive populacije. To su dušične organske baze niske molekulske mase koje mogu imati alifatsku, aromatsku ili heterocikličku strukturu. Široko su rasprostranjeni u fermentiranim pićima, uglavnom kao produkti dekarboksilacije slobodnih aminokiselina, koje su prekursori njihovog nastajanja (Vincenzini $i$ sur., 2009). U vinu se od BA najčešće nalaze histamin, putrescin, 2-feniletilamin i tiramin (Košmerl $i$ sur., 2013; Čuš $i$ sur., 2013; Soufleros i sur., 2007; Marcobal $i$ sur., 2005).

Europska Unija nije zakonski regulirala količinu biogenih amina u vinu, nego je samo dala preporuku, tzv. "Safety threshold values" (EFSA, 2011).

Općenito, toksičnom količinom u alkoholnim pićima smatra se $8-20 \mathrm{mgL}^{-1}$ za histamin, 25 - $40 \mathrm{mgL}^{-1}$ za tiramin, no feniletilamin negativne fiziološke učinke može imati već pri udjelu $3 \mathrm{mgL}^{-1}$ (Karovičova i Kohajdova, 2005). Na udio biogenih amina u vinu utječe čitav niz vitikulturnih i enoloških faktora. Neki amini prisutni su već u bobicama grožđa (Bover-Cid i sur., 2006; Kiss i sur., 2006), a naknadno neki faktori mogu ili povećati ili smanjiti koncentraciju prekursora i biogenih amina kako u grožđu, tako i u vinu. Među faktorima koji pogoduju stvaranju amina u vinu su i neki postupci tijekom proizvodnje vina (primarna i sekundarna fermentacija), kojima nastaju slobodne aminokiseline - prekursori BA (Martin-Alvarez i sur., 2006; Alcaide-Hidalgo i sur., 2007; Vincenzini $i$ sur., 2009). U industrijsku praksu se nakon dugog eksperimentalnog razvoja uvodi upotreba imobiliziranih stanica kvasca u sekundarnoj fermentaciji pjenušaca. $\mathrm{Na}$ ovaj način čuva se tradicionalna „Champenoise metoda" uz istovremenu eliminaciju proizvodnih koraka koji su vremenski i financijski najzahtjevniji.

Cilj ovoga rada bio je utvrditi postoje li razlike u profilu biogenih amina u pjenušcima proizvedenim pomoću imobiliziranih stanica kvasca u odnosu na potpuno tradicionalni postupak.

prof. dr. sc. Borislav Miličević, prof. dr. sc. Jurislav Babić, izv. prof. dr. sc. Đurđica Ačkar,

doc. dr. sc. Antun Jozinović, Vlado Previšić, dr. sc. Radoslav Miličević, prof. dr. sc. Drago Šubarić

Sveučilište Josipa Jurja Strossmayera u Osijeku, Prehrambeno-tehnološki fakultet Osijek, Franje Kuhača 20, 31000 0sijek (dackar@ptfos.hr)

Kutjevo d.d., Kralja Tomislava 1, 34340 Kutjevo

Progresys d.0.0., Ind. Park bb, HR-35400 Nova Gradiška 


\section{Materijali i metode \\ Proizvodnja vina}

Bazna vina proizvedena su iz grožđa sorti: Graševina (Welschriesling) - 25 \%, Pinot bijeli - 25 \%, Pinot sivi - 25 \% i Chardonnay - $25 \%$. Bazna vina proizvedena su klasičnim postupkom, fermentacijom s kvascem Fermol-Bouqet 125, u kontroliranom temperaturnom režimu $16-22{ }^{\circ} \mathrm{C}$. Prosječno trajanje fermentacije bilo je 42 dana.

Sekundarna fermentacija ("Champenois metoda") provedena je u bocama za pjenušce (750 $\mathrm{mL}$ ), u kojima je baznom vinu dodano $22 \mathrm{gL}^{-1}$ šećera. Jedna šarža proizvedena je pomoću imobiliziranih kvasaca prema prethodno opisanom postupku (Miličević i sur., 2017), a druga klasičnom metodom. Svaka šarža imala je 5 boca (paralela).

Analize su provedene nakon 10 mjeseci odležavanja (Europska komisija propisuje da je minimalni period odležavanja za pjenušce 9 mjeseci), nakon degoržacije. Boce su napunjene samim pjenušcem u svrhu proizvodnje Brut pjenušca (Liqueur d'expédition nije dodan). Za enološke analize iz uzorka je miješanjem na magnetskoj miješalici uklonjen $\mathrm{CO}_{2}$.

\section{Enološka analiza vina}

Enološka kvaliteta vina određena je klasičnim metodama prema O.I.V. $(2001 ; 2008)$ i hrvatskom zakonodavstvu (Zakon o vinu, NN96/03 s izmjenama i dopunama; Pravilnik o vinu NN 96/96 s izmjenama i dopunama). Fizikalno-kemijske analize uključivale se određivanje specifične mase, alkohola, ukupnog ekstrakta, ukupnih šećera, ukupnih i hlapljivih kiselina, ukupnog i slobodnog $\mathrm{SO}_{2}$, ukupnog dušika, pepela i tlaka.

\section{HPLC analiza biogenih amina u vinu}

Sadržaj biogenih amina u vinu određen je metodom prema Paris Soleas i sur. (1999), pomoću tekućinskog kromatografa HP 1100 (Agilent Technologies, Waldbronn, Njemačka), s autosamplerom i UV/VIS detektorom s promjenjivim valnim dužinama i fluorescentnim detektorom. Separacija je provedena nakon derivatizacije $s$ danzil kloridom (DNSCL), na koloni za kromatografiju obrnutih faza Zorbax Eclipse XDB C8 (150 mm × 4,6 mm, veličina čestica $5 \mu \mathrm{m}$ ) s predkolonom Meta Guard Inertsil C18. Standard za biogene amine je proizveden u Sigma-Aldrich, Steinheim, Njemačka, a DNSCL za flourescentni detektor u Merck, Darmstadt, Njemačka.

\section{Statistička analiza}

Statistička analiza provedena je pomoću Statistica ${ }^{\circ}$ softwarea, uz primjenu t-testa s pouzdanošću 95\%.

\section{Rezultati i rasprava}

Primjena imobiliziranih kvasaca relativno je nova tehnologija u proizvodnji pjenušavih vina. U usporedbi s tradicionalnom "Champenoise metodom" ima nekoliko prednosti u pogledu cijene i kontrole fermentacije. Rezultati dobiveni u ovom istraživanju (Tablica 1) pokazuju da je vino proizvedeno pomoću imobiliziranih stanica kvasca imalo blago povišeni udio alkohola (13,35 \% u odnosu na 12,99 \% kod klasičnog postupka). Količina alkohola u oba slučaja u skladu je s hrvatskim zakonodavstvom (Pravilnik o vinu, NN 96/96). Statistički značajna razlika uočena je u sadržaju ukupnog ekstrakta $\left(19,55 \mathrm{gL}^{-1}\right)$, koji je značajno niži kod postupka s imobiliziranim kvascima. Kod pjenušca proizvedenog klasičnim postupkom udio ukupnog ekstrakta bio je unutar preporučenog raspona. Ukupni ekstrakt odgovara karakteristikama kvalitetnih vina dobivenih iz odabranih sorti grožđa (Ribereau-Gayon i sur., 1998, O.I.V., 2001). Osim toga, u uzorcima proizvedenim s imobiliziranim kvascima bio je i niži udio ukupnih kiselina, što je $u$ skladu s istraživanjem Yajima i Yokotsuka (2001). Ukupni šećeri $\left(3,40 \mathrm{gL}^{-1}\right)$ bili su viši kod vina 
proizvedenog klasičnim postupkom nego kod uzoraka proizvedenih imobiliziranim kvascima $\left(2,65 \mathrm{gL}^{-1}\right)$, što je u skladu s rezultatima istraživanja Delfini $i$ sur. (2001).

Tablica 1. Rezultati enološke analize pjenušavih vina

Table 1. Results of enological analysis of sparkling wine

\begin{tabular}{|c|c|c|c|}
\hline & $\begin{array}{l}\text { Fermentacija imobiliziranim kvascima } \\
\text { (Immobilized yeast fermentation) }\end{array}$ & $\begin{array}{l}\text { Klasična fermentacija } \\
\text { (Classical fermentation) }\end{array}$ & $\mathrm{p}^{*}$ \\
\hline $\begin{array}{l}\text { Specifična masa } \\
\text { Specific mass } \\
\left(20 / 20^{\circ} \mathrm{C}\right)\left(\mathrm{gmL}^{-1}\right)\end{array}$ & $0,9916 \pm 0,0001$ & $0,9937 \pm 0,0003$ & 0,017 \\
\hline $\begin{array}{l}\text { Alkohol } \\
\text { Alcohol (\% vol.) }\end{array}$ & $13,35 \pm 0,14$ & $12,99 \pm 0,07$ & 0,056 \\
\hline $\begin{array}{l}\text { Ukupni ekstrakt } \\
\text { Total extract }\left(\mathrm{gL}^{-1}\right)\end{array}$ & $19,55 \pm 0,14$ & $22,40 \pm 0,35$ & 0,008 \\
\hline $\begin{array}{l}\text { Ukupni šećeri } \\
\text { Total sugars }\left(\mathrm{gL}^{-1}\right)\end{array}$ & $2,65 \pm 0,14$ & $3,40 \pm 0,07$ & 0,021 \\
\hline $\begin{array}{l}\text { Ukupne kiseline } \\
\text { Total acidity }\left(\mathrm{gL}^{-1}\right)\end{array}$ & $5,25 \pm 0,14$ & $5,92 \pm 0,10$ & 0,032 \\
\hline $\begin{array}{l}\text { Pepeo } \\
\text { Ash }\left(\mathrm{gL}^{-1}\right)\end{array}$ & $1,70 \pm 0,07$ & $2,00 \pm 0,07$ & 0,051 \\
\hline $\begin{array}{l}\text { Slobodni } \mathrm{SO}_{2} \\
\text { Free } \mathrm{SO}_{2}\left(\mathrm{mgL}^{-1}\right)\end{array}$ & $6,40 \pm 0,21$ & $5,92 \pm 0,03$ & 0,089 \\
\hline $\begin{array}{l}\text { Ukupni } \mathrm{SO}_{2} \\
\text { Total } \mathrm{SO}_{2}\left(\mathrm{mgL}^{-1}\right)\end{array}$ & $115,97 \pm 0,60$ & $115,16 \pm 0,23$ & 0,217 \\
\hline $\begin{array}{l}\text { Ukupni dušik } \\
\text { Total nitrogen }\left(\mathrm{mgL}^{-1}\right)\end{array}$ & $252,75 \pm 3,88$ & $222,75 \pm 3,88$ & 0,016 \\
\hline $\begin{array}{l}\text { Tlak } \\
\text { Pressure (bar) }\end{array}$ & $5,05 \pm 0,07$ & $5,10 \pm 0,07$ & 0,552 \\
\hline
\end{tabular}

*Vrijednosti parametara s podebljanim p vrijednostima statistički se značajno razlikuju

Način fermentacije imao je utjecaj i na sadržaj biogenih amina (Tablica 2) - u pjenušcima proizvedenim s imobiliziranim stanicama kvasca utvrđeno je $5,41 \mathrm{mgL}^{-1}$, dok je u klasično proizvedenim uzorcima taj sadržaj bio 7,24 $\mathrm{mgL}^{-1}$. Najzastupljeniji biogeni amin u uzorcima bio je histamin sa 2,23 $\mathrm{mgL}^{-1} \mathrm{u}$ uzorcima s imobiliziranim kvascima, odnosno 2,38 $\mathrm{mgL}^{-1} \mathrm{u}$ klasično proizvedenim uzorcima, vjerojatno zato što na produkciju histamina utječe čitavi niz enoloških faktora - od pripreme sirovine do kraja postupka fermentacije (Halasz i sur., 1994, Bauza $i$ sur., 1995, Gerbaux i Monamy, 2000., Landete i sur., 2005.). Nakon njega slijedi tripamin (1,66 i 1,81 $\mathrm{mgL}^{-1}$ ), kao u istraživanju Gloria $i$ sur. (1998).

Kako je prikazano u Tablici 2, koncentracija putrescina bila je relativno niska u svim uzorcima $\left(0,41\right.$ i $\left.0,48 \mathrm{mgL}^{-1}\right)$, vjerojatno zato što je fermentacija proizvedena komercijalnom čistom kulturom (Gerbaux i Monamy, 2000). Sličan trend pokazali su i ostali analizirani BA.

Način fermentacije imao je očiti utjecaj na koncentraciju putrescina, kadaverina i ß-feniletilamina, pri čemu je značajno niži udio navedenih spojeva utvrđen kod uzoraka proizvedenih tehnologijom imobiliziranih stanica kvasca. 
Tablica 2. Rezultati HPLC analize biogenih amina u pjenušavim vinima

Table 2. Results of HPLC analysis of biogenic amines in sparkling wine

\begin{tabular}{lccc}
\hline \multicolumn{1}{c}{$\begin{array}{c}\text { Biogeni amin } \\
(\text { Biogenic amine) } \\
\left(\mathrm{mgL}^{-1}\right)\end{array}$} & $\begin{array}{c}\text { Fermentacija imobiliziranim kvascima } \\
\text { (Immobilized yeast fermentation) }\end{array}$ & $\begin{array}{c}\text { Klasična fermentacija } \\
\text { (Classical fermentation) }\end{array}$ & $\mathrm{p}^{*}$ \\
\hline $\begin{array}{l}\text { Putrescin } \\
\text { Putrescine }\end{array}$ & $0,41 \pm 0,007$ & $0,48 \pm 0,007$ & $\mathbf{0 , 0 1 0}$ \\
\hline $\begin{array}{l}\text { Kadaverin } \\
\text { Cadaverine }\end{array}$ & $0,24 \pm 0,007$ & $0,49 \pm 0,014$ & $\mathbf{0 , 0 0 2}$ \\
\hline $\begin{array}{l}\text { B-feniletilamin } \\
\beta \text {-Phenylethylamine }\end{array}$ & $0,35 \pm 0,028$ & $1,47 \pm 0,240$ & $\mathbf{0 , 0 2 2}$ \\
\hline $\begin{array}{l}\text { Spermidin } \\
\text { Spermidine }\end{array}$ & $0,16 \pm 0,021$ & $0,23 \pm 0,028$ & 0,121 \\
\hline $\begin{array}{l}\text { Triptamin } \\
\text { Tryptamine }\end{array}$ & $1,66 \pm 0,042$ & $1,81 \pm 0,106$ & 0,195 \\
\hline $\begin{array}{l}\text { Serotonin } \\
\text { Serotonine }\end{array}$ & $0,16 \pm 0,021$ & $0,14 \pm 0,021$ & 0,440 \\
\hline $\begin{array}{l}\text { Tiramin } \\
\text { Tyramine }\end{array}$ & $0,18 \pm 0,007$ & $0,22 \pm 0,035$ & 0,257 \\
\hline $\begin{array}{l}\text { Histamin } \\
\text { Histamine }\end{array}$ & $2,23 \pm 0,028$ & $2,38 \pm 0,148$ & 0,284 \\
\hline $\begin{array}{l}\text { Ukupno } \\
\text { Total }\end{array}$ & $5,41 \pm 0,091$ & $7,24 \pm 0,558$ & $\mathbf{0 , 0 4 4}$ \\
\hline
\end{tabular}

*Vrijednosti parametara s podebljanim p vrijednostima statistički se značajno razlikuju

\section{Zaključci}

Rezultati dobiveni u ovom istraživanju pokazuju da način provedbe fermentacije utječe na najzastupljenije biogene amine u vinu: histamin, putrescin, kadaverin, ß-feniletilamin i tiramin . Primjenom imobiliziranih stanica kvasca u sekundarnoj fermentaciji pjenušavih vina značajno se smanjuje udio navedenih spojeva u pjenušavim vinima. Osim toga, nije potrebno okretanje boca tijekom sekundarne fermentacije, što značajno olakšava njenu provedbu. Iz svega navedenoga može se zaključiti da je fermentacija s imobiliziranim kvascima obećavajući pristup proizvodnji pjenušavih vina.

\section{Literatura}

Alcaide-Hidalgo, J.M., Moreno-Arribas, M.V., Martın-Alvarez, P.J., Polo M.C. (2007) Influence of malolactic fermentation, postfermentative treatments and ageing with lees on nitrogen compounds of red wines, Food Chem. $103,572-581$.

Anonymous - Regulations of wine (1996 and 2000) Official Gazzete of Republic of Croatia. no. 96 and 57. Official Gazzete, Zagreb, Croatia.

Bauza, T., Blaise, A., Daumas, F., Cabanis, J.C. (1995) Determination of biogenic amines and their precursor amino acids in wines of the Vallee du Rhone by high-perfomance liquid chromatography with precolumn derivatisation and fluorimetric detection, Journal of Chromatography A, 707, 373-379.

Bover-Cid, S., Iquierdo-Pulido, M., Marina-Font, A., Vidal-Carou, M.C. (2006) Biogenic mono-, di- and polyamine contents in Spanish wines and infl uence of a limited irrigation, Food Chem. 96, 43-47.

Čuš, F., Bach, B., Barnavon, L., Žnidaršič Pongrac, V. (2013) Analytical determination of Dolenjska region wines quality, Food control 33, 274-280.

Delfini, C., Cocito, C.H., Bonino, M., Schellino, R., Gaia, P., Baiocchi, C. (2001) Definitive evidence for the actual contribution of yeast in the transformation of neutral precursors of grape aromas, Journal of Agricultural and Food Chemisty 48, 1789 - 1798.

EFSA Scientific Opinion on risk based control of biogenic amine formation in fermented foods. EFSA Journal, 9(10), 2393.

European Commission. (1999) Council Regulation (EC) No. 1493/1999 of 17 May 1999 on the common organisation of the market in wine. OJ L 179, 14.7.1999 
Gerbaux, V., Monamy, C. (2000) Biogenic amines in Burgundy wines. Content and origin in wines, Rev. Fr. Oenol. $183,25-28$

Gloria, M.B.A., Watson, B.T., Simon-Sarkadi, L., Daeschel, M.A. (1998) A survey of biogenic amines in Oregon Pinot noir and Cabernet Sauvignon wines, Am. J. Enol. Vitic. 49, 279-282.

Halasz, A., Barath, A., Simon-Sarkadi, L., Holzapfel, W. (1994) Biogenic amines and their production by microrganisms in food, Trends Food Sci. Technol. 5, 42-49.

Karovičova, J., Kohajdova, Z. (2005 Biogenic amines in food, Chemical Papers 59(1), 70-79.

Kiss, J., Korbasz, M., Sass-Kiss, A. (2006): Study of amine composition of botrytized grape berries, J. Agr. Food Chem. 53, 8909-8918.

Košmerl, T., Šućur, S., Prosen, H. (2013) Biogenic amines in red wine: The impact of technological processing of grape and wine, Acta agriculturae Slovenica 101, $249-261$.

Landete, J.M., Ferrer, S., Pardo, I. (2005) Which lactic acid bacteria are responsible for histamine production in wine, J.Appl. Microbiol. 99, 580-586.

Marcobal, A., Polo, M.C., Martin-Alvarez, P.J, Moreno-Arribas, M.V. (2005) Biogenic amine content of red Spanish wines: comparation of a direct ELISA and an HPLC method for the determination of histamine in wines, Food Res. Int. 38, 387-394.

Martin-Alvarez, P.J., Macrobal, A., Polo, C., Moreno-Arribas, M.V. (2006) Influence of technological practices on biogenic amine contents in red wine, Eur. Food Res. Technol. 222, 420-424.

Miličević, B., Babić, J., Ačkar, Đ., Miličević, R., Jozinović, A., Jukić, H., Babić, V., Šubarić, D. (2017) Sparkling Wine Production by Immobilised Yeast Fermentation. Czech J. Food Sci. 35(2), 171-179.

(http://www.agriculturejournals.cz/web/cjfs.htm?type=article\&id=194_2016-CJFS)

O.I.V. International Code of Oenological Practices, (2001).

O.I.V. (2008) Recuéil des Méthodes Internationales d'Analyse des Vins et des Môuts. Organisation Internationale de la Vigne et du Vin,

Paris Soleas, G.J., Carey, M., Goldberg, D.M. (1999) Method development and cultivar-related differences of nine biogenic amines in Ontario wines, Food Chem. 64, 49-58.

Pravilnik o vinu, NN 96/96, 7/97, 117/97, 57/00

Ribereau-Gayon, P., Glories, Y., Maujean, A., Dubordieu, D., (1998) Traité d'Oenologie 2. Chimie du Vin. Stabilisation et Traitements. Pariz: Dunod.

Soufleros, E.H., Bouloumpasi, E., Zotou, A., Loukou, Z. (2007) Determination of biogenic amines in Greek wines by HPLC and ultraviolet detection aft er dansylation and examination of factors aff ecting their presence and concentration, Food Chem. 101, 704-716.

Vincenzini, M., Guerrini, S., Mangani, S., Granchi, L. (2009) Amino Acid Metabolisms and Production of Biogenic Amines and Ethyl Carbamate. In: Biology of Microorganisms on Grapes, in Must and in Wine,Springer-Verlag, Berlin Heidelberg, pp. 167-176.

Yajima, M., Yokotsuka, K., (2001): Volatile Compound Formation in White Wines Fermented Using Immobilized and Free Yeast, Am. J. Enol. Vitic. 52(3), 210-218.

Zakon o vinu, NN 96/03, 25/09, 22/11, 55/11, 82/13, 14/14

\section{Presence of biogenic amines in sparkling wine influenced by the immobilized yeast cells technology}

\section{Abstract}

Recent trends in food safety are promoting an increasing search for trace compounds that can affect human health, biogenic amines belong to this group of substances. Biogenic amines are basic nitrogenous low molecular weight compounds with biological activity. Biogenic amines in the wine can be formed from their precursors by various microorganisms present in the wine, at any stage of production. The aim of the present work was to investigate the changes of the content of biogenic amines in sparkling wines produced by fermentation method with immobilized yeast cells. Biogenic amines were quantified using a reversedphase high performance liquid chromatography (HPLC). Total amount of biogenic amines was $5.41 \mathrm{mgL}^{-1}$ in wines made with immobilized yeast cells and $7.24 \mathrm{mgL}^{-1}$ in wines made in classical fermentation process. From the results obtained in this study, it can be concluded that immobilized yeast cells technology can influence the formation of biogenic amines.

Key words: biogenic amines, immobilized yeast cells, sparkling wine 